Article

\title{
How Photocatalyst Dosage and Ultrasound Application Influence the Photocatalytic Degradation Rate of Phenol in Water: Elucidating the Mechanisms Behind
}

\author{
Wim Van de Moortel ${ }^{1}$, Mohammadreza Kamali ${ }^{1}$, Kristel Sniegowski ${ }^{2}$, Leen Braeken ${ }^{2}$, \\ Jan Degrève ${ }^{3}$, Jan Luyten ${ }^{1}$ and Raf Dewil ${ }^{1, * \mathbb{D}}$ \\ 1 Process and Environmental Technology Lab, Department of Chemical Engineering, KU Leuven B, \\ 2860 Sint-Katelijne-Waver, Belgium; wim.vandemoortel@hotmail.com (W.V.d.M.); \\ Mohammadreza.kamali@kuleuven.be (M.K.); jan.luyten@umicore.com (J.L.) \\ 2 Centre for Industrial Process Technology, Department of Chemical Engineering, KU Leuven B, \\ 3590 Diepenbeek, Belgium; kristel.sniegowski@kuleuven.be (K.S.); leen.braeken@kuleuven.be (L.B.) \\ 3 Bio- \& Chemical Systems Technology, Reactor Engineering and Safety Section, \\ Department of Chemical Engineering, KU Leuven B, 3001 Leuven, Belgium; jan.degreve@kuleuven.be \\ * Correspondence: raf.dewil@kuleuven.be; Tel.: +32-15-688229
}

Received: 24 December 2019; Accepted: 9 May 2020; Published: 11 June 2020

\begin{abstract}
Photocatalysis is of high interest for the treatment of wastewater containing non-biodegradable organic components. In this work, the photocatalytic degradation of phenol by $\mathrm{TiO}_{2}$ photocatalysis was assessed, the influence of ultrasound (US) treatment was evaluated, and the mechanisms behind it were elucidated. It was shown that the $\mathrm{TiO}_{2}$ concentration (in suspension) has a large influence on the degradation kinetics. At high $\mathrm{TiO}_{2}$ concentrations, a reduced efficiency was observed due to the shielding of the UV light by $\mathrm{TiO}_{2}$ particles. US treatment effectively increased phenol degradation by improving the mass transfer while it was shown by the experimental data that particle deagglomeration did not play a significant role. The degradation mainly occurred through indirect phenol oxidation by hydroxyl $\left(\mathrm{OH}^{*}\right)$ radicals, which were formed in situ at the surface of the photocatalyst. Finally, based on the partial least squares (PLS) methodology, a mathematical model was developed, representing phenol degradation as a function of the selected process conditions.
\end{abstract}

Keywords: phenol; advanced oxidation processes; ultrasound; photocatalysis; deagglomeration

\section{Introduction}

Phenol is one of the most widespread industrial wastewater contaminants. It normally exists in high concentrations in the effluent of various industrial sectors, including the chemical, petrochemical and pharmaceutical industry, refineries and oil field activities, coal processing, and olive oil production [1]. Because of its high toxicity, it is defined as a priority pollutant. Various techniques have been developed for its removal from the effluents [2], including (i) classical separation techniques (e.g., distillation, liquid-liquid extraction, adsorption, membrane separation) [3,4], (ii) biochemical treatments (aerobic and anaerobic) [5], and (iii) advanced oxidation processes (e.g., wet air oxidation, ozonation, peroxide wet oxidation, electrochemical and photocatalytic oxidation) [6-9]. Apart from its industrial relevance, phenol is frequently described in the literature as a model component to assess the effectiveness of various advanced oxidation processes (AOP) to remove low biodegradable or toxic organic components from wastewater. Using phenol, therefore, enables a comparative evaluation of the treatments reported in different literature sources. 
Photocatalysis is currently of high interest for the degradation of non-biodegradable organic components from wastewater and various studies have been dedicated to this process. The physical and chemical mechanisms underlying photocatalysis for pollutant degradation in water were described by Wang et al. [10]. In short, UV light absorbed by the photocatalyst results in the promotion of electrons to a higher energy band (from the valence band to the conduction band). This instable situation results in the ability to: (i) directly degrade (mostly oxidize) adsorbed organic pollutants (direct photocatalytic degradation); and (ii) generate $\mathrm{OH}^{*}$ (hydroxyl) radicals from water molecules, which are, in turn, capable to readily oxidize organic components present in the wastewater (indirect photocatalytic degradation). Both mechanisms contribute to the overall photocatalytic degradation rate. The presence of dissolved oxygen in the water can also potentially promote the efficiency of the photocatalytic process by scavenging the promoted electrons in the conduction band of the semiconductor upon excitation [11].

Since UV light is required for photocatalysis to occur, the possibility for the direct degradation of organic components by UV (photolysis) is always present in a photocatalytic system. Direct photolysis of phenol by UV was previously studied by Chun et al. [12]. They concluded that a complete degradation of phenol is feasible in the presence of dissolved oxygen, whereas the degradation efficiency remains limited if no oxygen is present. In the latter case, the complete mineralization of phenol could not be achieved.

Ultrasound (US) was shown to be a promising technology in wastewater treatment [13-16]. Low frequency $(<1 \mathrm{MHz})$ US waves cause the so-called cavitation process when submitted to an aqueous medium. The alternating high and low pressures generated by the acoustic waves create bubbles, which grow in time. Once a critical bubble diameter is reached, the bubbles implode, locally generating high temperatures and pressures. These transient, localized hotspots drive high-energetic chemical reactions such as the creation of hydroxyl $\left(\mathrm{OH}^{*}\right)$ radicals [17]. Furthermore, organic components encountering these cavitation bubbles can undergo thermal degradation [18]. In combination with a (photo)catalyst, the application of US results in the following synergistic effects [19]: part of the jet streams generated during the cavitation bubble implosion are directed towards the catalyst surface, resulting in an intense micromixing and an increased mass transfer of reagents and products towards and from the catalyst surface; cleaning of the catalyst surface by the same jet streams occurs; and deagglomeration of catalyst particles takes place. These particles tend to agglomerate when suspended in an aqueous solution because of Van der Waals forces. US effectively tears apart these agglomerates, resulting in smaller particles and hence an increased surface-volume ratio.

Because of these beneficial properties, various studies were dedicated to describing the effects of a combined US/photocatalysis treatment on different types of wastewater. The combined effect of sonolysis and photocatalysis can considerably promote the production of high reactive-free radicals in the medium [20,21]. A short overview of some relevant papers is provided in Table 1.

Table 1. Overview of some recent papers on the combined ultrasound (US)/photocatalytic treatment of wastewater.

\begin{tabular}{ccc}
\hline Reference & Process & Conclusion \\
\hline Kidak and Ince [22] & $\begin{array}{c}\mathrm{UV} / \mathrm{US}(\mathrm{UV}=254 \mathrm{~nm} \\
\mathrm{US}=300 \mathrm{kHz})\end{array}$ & $\begin{array}{c}\text { Photolytic/sonochemical decomposition of phenol by } \\
\mathrm{UV} \text { irradiation was insignificant, while the operation } \\
\text { under ultrasonic irradiation was efficient }\end{array}$ \\
\hline Harada and Tanaka [23] & $\mathrm{UV} / \mathrm{TiO}_{2} / \mathrm{US}$ & $\begin{array}{c}\text { Synergistic effect of combining sonolysis and } \\
\text { photocatalysis was confirmed in an Ar atmosphere }\end{array}$ \\
\hline Mrowetz et al. [24] & $\mathrm{UV} / \mathrm{TiO}_{2} / \mathrm{US}$ & $\begin{array}{c}\text { A synergistic effect between sonolysis and } \\
\text { photocatalysis was observed }\end{array}$ \\
\hline Naghizadeh et al. [26] $[25]$ & $\mathrm{UV} / \mathrm{TiO}_{2} / \mathrm{US}$ & $\begin{array}{c}\text { Diethyl phthalate was successfully removed from the } \\
\text { wastewater by sonophotocatalysis }\end{array}$ \\
\hline & $\mathrm{UV} / \mathrm{TiO}_{2} / \mathrm{US}$ & $\begin{array}{c}\text { The effect of US power on Chitosan degradation was } \\
\text { shown. The degradation was increased by an } \\
\text { increasing power }\end{array}$ \\
\hline
\end{tabular}


The aim of the present research is to study the degradation of phenol in synthetic wastewater using the combination of $\mathrm{UV} / \mathrm{TiO}_{2}$, with the main goal being the evaluation of the synergistic effect of US application at $24 \mathrm{kHz}$. The particle size of the $\mathrm{TiO}_{2}$ will be measured to show the effect on deagglomeration of the particles and to be able to attribute positive effects of US to deagglomeration or enhanced mass transfer to the catalyst surface. An experimental design methodology and surface response methodology are used to evaluate the influence of the initial concentration of phenol, UV intensity, ultrasonic power, $\mathrm{TiO}_{2}$ dosage, and reaction time.

\section{Materials and Methods}

\subsection{Experimental Setup}

All experiments were carried out in a $3 \mathrm{~L}$ batch reactor with an active volume of $2 \mathrm{~L}$ (Figure 1). An ultrasonic probe generating $24 \mathrm{kHz}$ acoustic waves with a variable power output between 30 and $100 \mathrm{~W}$ (Bandelin Sonoplus generator combined with UW 3200 Probe) was placed eccentrically in the reactor. A low-pressure mercury UV lamp $(11 \mathrm{~W}$, UV-C lamp with a maximum UV light emission at a wavelength of $254 \mathrm{~nm}$ ) was placed slightly off-center in the vessel.

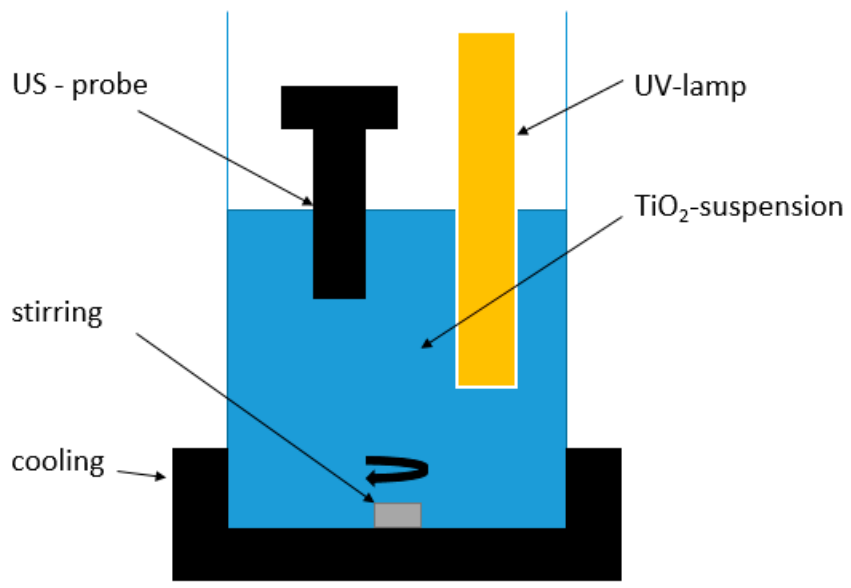

Figure 1. Experimental set-up.

$\mathrm{TiO}_{2}$ (crystalline structure: anatase) was obtained from Acros Organics (Geel, Belgium). The diameter, specific surface area and band gap energy of the $\mathrm{TiO}_{2}$ were $100-400 \mathrm{~nm}, 55 \mathrm{~m}^{2} / \mathrm{g}$, and $3.13 \mathrm{eV}$ (UV absorption at $356 \mathrm{~nm}$ or lower), respectively. $\mathrm{TiO}_{2}$ was added to the reactor content at successive concentrations of $0.01 \mathrm{~g} / \mathrm{L}, 0.1 \mathrm{~g} / \mathrm{L}, 0.5 \mathrm{~g} / \mathrm{L}$, and $1 \mathrm{~g} / \mathrm{L}$. Samples of $2 \mathrm{~mL}$ were taken after $0,10,20,30,45$, and $60 \mathrm{~min}$ reaction time. When $\mathrm{TiO}_{2}$ was used, the samples were filtered through cellulose filters $(0.1 \mu \mathrm{m})$, prior to analysis. Cooling water was continuously circulated around the reactor, to avoid a temperature increase caused by energy dissipation of the US waves and UV lamp. The temperature was hence kept constant at $20^{\circ} \mathrm{C}\left( \pm 1^{\circ} \mathrm{C}\right)$. The particle size distribution of the $\mathrm{TiO}_{2}$ photocatalyst particles was determined using a Malvern Mastersizer 2000 laser diffraction particle size analyzer.

The water used in the experiments consisted of demineralized water $(\mathrm{pH}=5.8)$, in which 5-10 ppm phenol (Acros Organics, Geel, Belgium) was dissolved. Because the main aim of this paper was to identify the determining mechanisms underlying the photocatalytic phenol degradation, the aqueous solution was kept as simple as possible, i.e., no organics were added as matrix components to simulate a real wastewater. In some tests, however, t-butanol (Acros Organics, Geel, Belgium) was added as a radical scavenger. All reagents were of analytical grade and used as purchased. 


\subsection{Methods of Analysis}

Phenol concentration was analyzed using a DIONEX HPLC, using water/methanol (68/32 $\rightarrow$ 20/80) as eluent at a flow rate of $1 \mathrm{~mL} / \mathrm{min}$, a C18 column (Grace 4.6 ID X $250 \mathrm{~mm}$ ), and a UV detector set at a wavelength of $270 \mathrm{~nm}$. The volume of the injected sample was $20 \mu \mathrm{L}$.

The UV absorbance of the reaction mixtures (including the suspended $\mathrm{TiO}_{2}$ was measured in a Hach Lange UV-Vis spectrometer at a wavelength of $254 \mathrm{~nm}$. Using the obtained values, the evolution of UV light intensity (I) in the reactor as a function of the distance R to the UV lamp was calculated using a linear relation as suggested by the Lambert-Beer Law.

\subsection{Kinetic Analysis}

The removal of phenol from the aqueous phase is achieved by a combination of three different mechanisms, i.e., adsorption, chemical oxidation by the generated radicals, and direct photolysis. This combination results in the following kinetic Equation (1):

$$
\frac{d C_{\text {phenol }}}{d t}=\frac{k_{1} K_{A} C_{\text {phenol }}}{1+K_{A} C_{\text {phenol }}}+k_{2} C_{\mathrm{OH}} C_{\text {phenol }}+k_{3} C_{\text {phenol }}
$$

where $C_{\text {phenol }}$ is the concentration of phenol at time $t ; k_{1}$ is the reaction rate constant for the reaction occurring at the surface; $k_{2}$ is the reaction rate constant for the reaction between $\mathrm{OH}^{*}$ radicals and phenol; $k_{3}$ is the reaction rate constant for direct photolysis; and $\mathrm{C}_{\mathrm{OH}}$ is the concentration of $\mathrm{OH}^{*}$ radicals in the aqueous medium and $K_{A}$ the adsorption rate constant.

As shown in the results section, the experimental results showed that pure adsorption phenomena could be neglected, and, therefore, the first term in the equation is assumed to be zero. Moreover, because the radical concentration can be assumed to be constant (continuous creation at the catalyst surface by a constant UV intensity), an apparent reaction rate constant $\mathrm{k}^{\prime}$ can be defined, with $k^{\prime}=k_{2} \mathrm{COH}_{\mathrm{OH}}+k_{3}$. The equation then translates into Equation (2):

$$
\frac{d C_{\text {phenol }}}{d t}=0+k_{2} C_{O H} C_{\text {phenol }}+k_{3} C_{\text {phenol }}=k \prime C_{\text {phenol }}
$$

This means that the photocatalytic degradation of phenol follows apparent first order kinetics. The apparent reaction rate constant $k^{\prime}$ was graphically determined by plotting $\ln \left(C_{\text {phenol }} / C_{\text {phenol, }, 0}\right)$ versus time. The slope of the linear curve obtained equals $k^{\prime}$, following Equation (3):

$$
\frac{d C_{\text {phenol }}}{d t}=k^{\prime C_{\text {phenol }}} \Rightarrow \ln \frac{C_{\text {phenol }}}{C_{\text {phenol }, 0}}=k \prime t
$$

The experimental data were fitted by linear regression, using a partial least squares routine.

\subsection{Experimental Design and Statistical Analysis}

The obtained experimental results were used to: (i) identify and quantify the importance of different operating parameters, and (ii) develop an empirical model to predict phenol degradation as function of several variables. The variables considered for this study were: initial phenol concentration, reaction time, power of the acoustic field, and $\mathrm{TiO}_{2}$ concentration. The response variable was the phenol concentration relative to the initial phenol concentration. The design matrix of the experimental design is provided in Table 2. A linear regression model was obtained using partial least squares regression. 
Table 2. Design matrix and results of the treatment of the synthetic wastewater. All the runs were performed at a reaction time of $60 \mathrm{~min}$.

\begin{tabular}{|c|c|c|c|c|c|c|c|}
\hline Assay & $\mathrm{C}_{0, \mathrm{phenol}}(\mathrm{ppm})$ & UV (W) & $\mathrm{TiO}_{2}(\mathrm{~g} / \mathrm{L})$ & US (W) & $\mathrm{C} / \mathrm{C}_{0}(-)$ & $k^{\prime}(1 / s)$ & $R^{2}$ \\
\hline 1 & 5 & 11 & 0 & 0 & 0.511 & -0.0118 & 0.978 \\
\hline 2 & 5 & 11 & 0.01 & 0 & 0.427 & -0.0146 & 0.990 \\
\hline 3 & 5 & 11 & 0.1 & 0 & 0.330 & -0.0192 & 0.995 \\
\hline 4 & 5 & 11 & 0.5 & 0 & 0.623 & -0.00777 & 0.995 \\
\hline 5 & 5 & 11 & 1 & 0 & 0.689 & -0.00665 & 0.979 \\
\hline 6 & 5 & 11 & 0 & 50 & 0.458 & -0.0127 & 0.978 \\
\hline 7 & 5 & 11 & 0.01 & 50 & 0.317 & -0.0200 & 0.999 \\
\hline 8 & 5 & 11 & 0.1 & 50 & 0.260 & -0.0224 & 0.987 \\
\hline 9 & 5 & 11 & 0.5 & 50 & 0.337 & -0.0180 & 0.969 \\
\hline 10 & 5 & 11 & 1 & 50 & 0.454 & -0.0129 & 0.997 \\
\hline 11 & 5 & 11 & 0 & 100 & 0.526 & -0.0120 & 0.987 \\
\hline 12 & 5 & 11 & 0.01 & 100 & 0.220 & -0.0227 & 0.822 \\
\hline 13 & 5 & 11 & 0.1 & 100 & 0.113 & -0.0363 & 0.972 \\
\hline 14 & 5 & 11 & 0.5 & 100 & 0.293 & -0.0203 & 0.985 \\
\hline 15 & 10 & 11 & 0 & 0 & 0.733 & -0.00491 & 0.999 \\
\hline 16 & 10 & 11 & 0.5 & 0 & 0.711 & -0.00714 & 0.848 \\
\hline 17 & 10 & 11 & 1 & 0 & 0.705 & -0.00584 & 0.993 \\
\hline 18 & 10 & 11 & 0 & 50 & 0.660 & -0.00796 & 0.942 \\
\hline 19 & 10 & 11 & 0.01 & 50 & 0.455 & -0.0123 & 0.956 \\
\hline 20 & 10 & 11 & 0.1 & 50 & 0.402 & -0.0154 & 0.965 \\
\hline 21 & 10 & 11 & 0.5 & 50 & 0.488 & -0.0106 & 0.949 \\
\hline 22 & 10 & 11 & 0.1 & 100 & 0.555 & -0.00341 & 0.909 \\
\hline 23 & 10 & 11 & 0 & 100 & 0.520 & -0.0102 & 0.984 \\
\hline 24 & 5 & 0 & 0.1 & 0 & 0.981 & -0.000840 & 0.555 \\
\hline 25 & 5 & 0 & 0.1 & 50 & 0.981 & -0.000530 & 0.228 \\
\hline
\end{tabular}

\section{Results}

\subsection{Influence of $\mathrm{TiO}_{2}$ Concentration}

The influence of the $\mathrm{TiO}_{2}$ catalyst concentration on the phenol degradation reaction kinetics was first investigated without the application of US. The decrease in phenol concentration $\mathrm{C}$ as a function of time (expressed as $\mathrm{C} / \mathrm{C}_{0}$ ) is depicted in Figure 2.

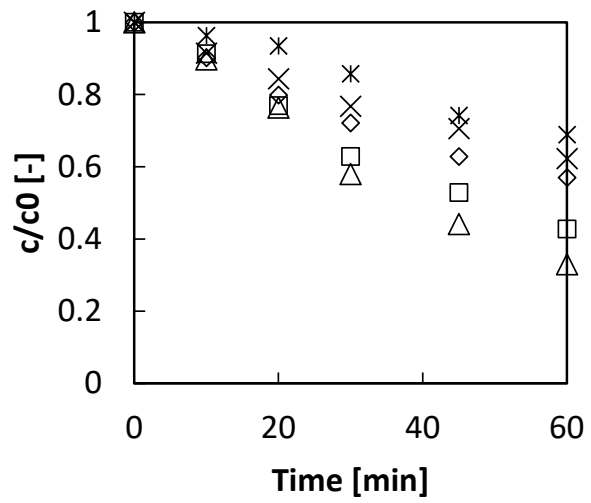

(a)

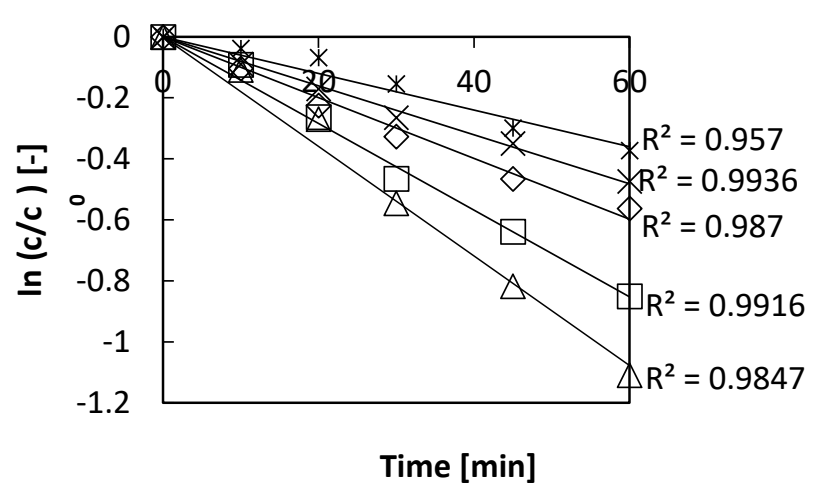

(b)

Figure 2. The degradation of phenol by $\mathrm{UV} / \mathrm{TiO}_{2}$ at different $\mathrm{TiO}_{2}$-dosages (a) and kinetic evaluation of the degradation reaction (b) for different $\mathrm{TiO}_{2}$ concentration $(0 \mathrm{~g} / \mathrm{L}(\diamond) ; 0.01 \mathrm{~g} / \mathrm{L}(\square) ; 0.1 \mathrm{~g} / \mathrm{L}(\Delta) ; 0.5 \mathrm{~g} / \mathrm{L}$ $(\mathrm{x}) ; 1 \mathrm{~g} / \mathrm{L}(*))$. 
It was observed that a significant phenol degradation occurred via direct photolysis (i.e., without the presence of the photocatalyst). After $60 \mathrm{~min}$ reaction time, only $51 \%$ of the initial phenol concentration remained (values indicated in Table 2). This observation is in accordance with the findings of Chun et al. [12], who already pointed out that direct photolysis is able to degrade phenol in wastewater.

The addition of suspended $\mathrm{TiO}_{2}$ photocatalyst to the reactor enhanced the degradation efficiency, but only at low $\mathrm{TiO}_{2}$ concentrations. At $\mathrm{TiO}_{2}$ concentrations $0.01 \mathrm{~g} / \mathrm{L}$ and $0.1 \mathrm{~g} / \mathrm{L}, 42.7 \%$ and $33.0 \%$ of phenol remained after $1 \mathrm{~h}$ reaction time, respectively. However, at higher $\mathrm{TiO}_{2}$ concentrations, a considerable decrease in degradation efficiency took place, even to a lower level than direct photolysis (without $\mathrm{TiO}_{2}$ ). For $\mathrm{TiO}_{2}$ concentrations of $0.5 \mathrm{~g} / \mathrm{L}$ and $1 \mathrm{~g} / \mathrm{L}$, the remaining fraction of phenol after $1 \mathrm{~h}$ reaction time was as high as $62.3 \%$ and $68.0 \%$, respectively.

The same trend was (as expected) noticed in the reaction kinetics. In Figure $2 \mathrm{~b} \ln (\mathrm{C} / \mathrm{Co})$ was plotted versus time. The linear trends that were obtained (high $R^{2}$ values for a linear fit of the data points) suggest that first order reaction kinetics governed the degradation reactions for all $\mathrm{TiO}_{2}$ concentrations. The reaction rate constant $k^{\prime}$ of each reaction was calculated as the slope of the lines and their values are included in Table 2. Here again, an increase in $\mathrm{k}^{\prime}$ was observed for increasing $\mathrm{TiO}_{2}$ concentration up to $0.1 \mathrm{~g} / \mathrm{L}$, followed by a decrease at higher concentrations.

An explanation for the observed influence should be sought in the effective illumination of the photocatalyst in the reactor. The observed reaction kinetics are indeed governed by two aspects: (i) the actual $\mathrm{TiO}_{2}$ mass (and hence its surface area) available in the reactor, expressed in this study in terms of concentration; and (ii) the effective illumination of the catalyst surface by the UV light. At higher suspended $\mathrm{TiO}_{2}$ concentrations, more surface area is available in the reactor, but the particles will induce shielding and dispersion of the UV light, hence the reactor volume is only partially illuminated.

To quantify this phenomenon, the UV intensity in the reactor was measured as a function of the distance to the UV lamp for the different $\mathrm{TiO}_{2}$ concentrations applied in this study. The results are depicted in Figure 3. From this figure, it becomes clear that for the two highest $\mathrm{TiO}_{2}$ concentrations, $(0.5 \mathrm{~g} / \mathrm{L}$ and $1 \mathrm{~g} / \mathrm{L})$ the UV intensity dropped very fast, and only a very small volume in the reactor was illuminated. From these data, the mass of $\mathrm{TiO}_{2}$ receiving at least $50 \%$ of the initial UV intensity was calculated and is depicted in Figure 4. Here again, the maximum was observed for $0.1 \mathrm{~g} \mathrm{TiO}_{2} / \mathrm{L}$, which closely correlates with the results of reaction kinetic constants.

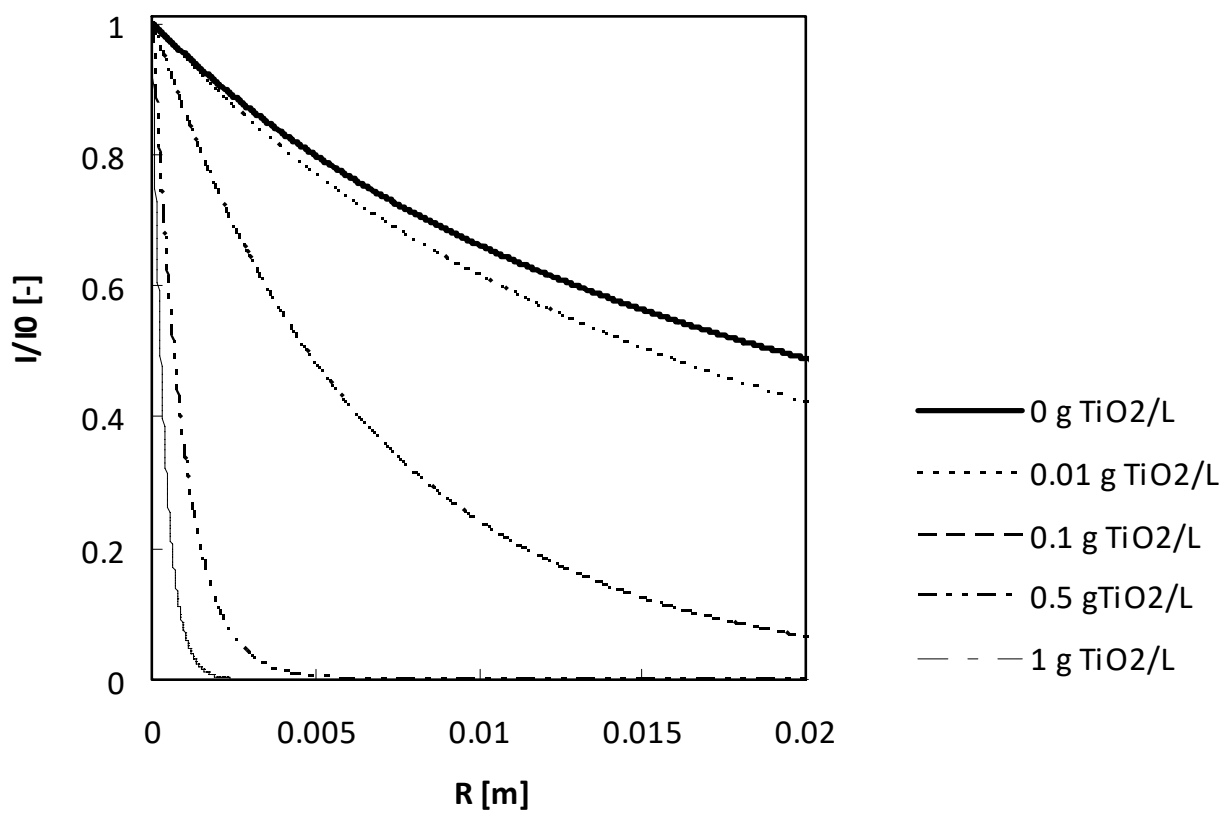

Figure 3. Decrease of UV-intensity compared to the distance to the UV lamp. 


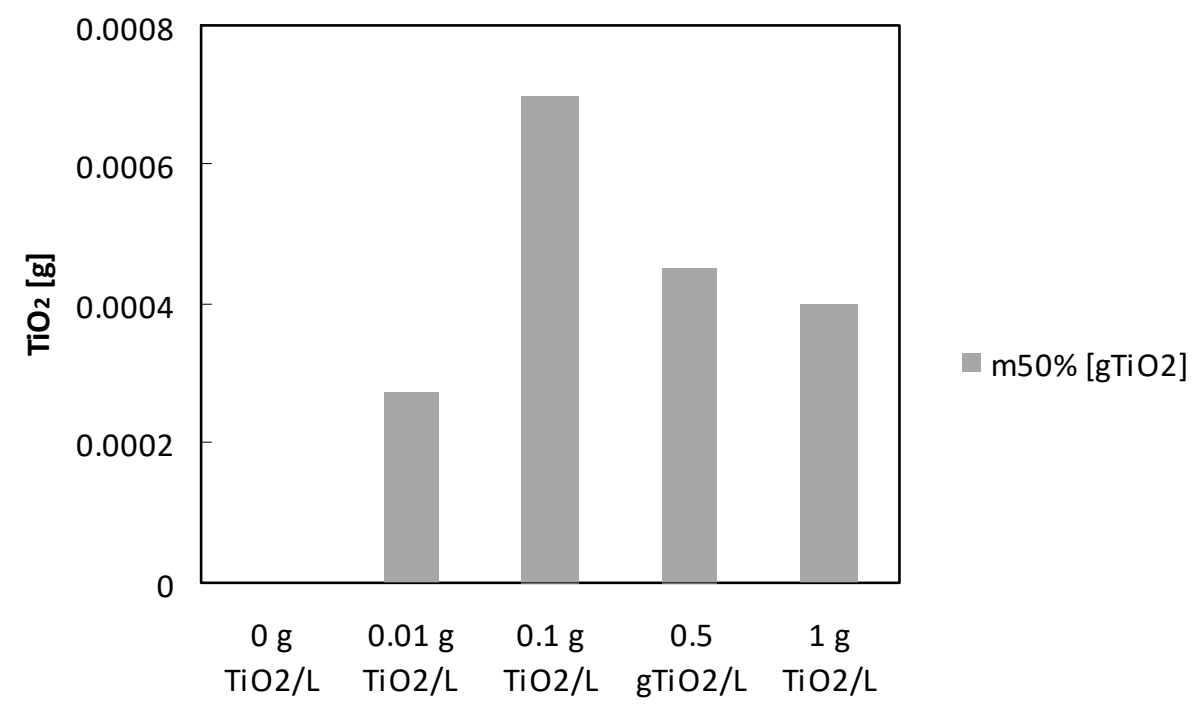

Figure 4. Amount of catalyst that receives $50 \%$ or more of initial intensity of the lamp.

The importance of an effective illumination is further illustrated by the fact that when the UV lamp was switched off, no significant degradation of phenol occurred (see assay 24 in Table 2). The limited penetration depth of the UV light at high $\mathrm{TiO}_{2}$ concentrations hence resulted in a large reduction of the effective volume in the reactor where the reactions take place (direct photolysis and catalytic degradation), leading to lower overall degradation kinetics (calculated on the total reactor volume).

\subsection{Influence of Ultrasound Application}

The application of US on the photocatalytic system can enhance the photocatalytic degradation of phenol because of three distinct effects: (i) deagglomeration of the catalyst, leading to smaller $\mathrm{TiO}_{2}$ particles and hence a higher specific surface on which the reaction (either generation of $\mathrm{OH}^{*}$ radicals or direct photocatalytic degradation of phenol) can take place; (ii) the improvement of mass transfer from and to the catalytically active surface; and (iii) the cleaning of the catalytic surface. The latter effect will only play an important role in the long-term (when the catalyst surface effectively becomes polluted) or for "dirty" wastewater containing a lot of only partially soluble organic material, and will certainly not have any influence on the phenol degradation in the lab scale system applied in the current study. Both of the other effects, however, do have a potential influence on the reaction rates observed in the applied model system. In this section, the relative influence of each effect will be determined.

The effects of the US treatment for the different reaction conditions are included in Table 2. As an example, Figure 5 illustrates the differences in phenol degradation as a function of US power input for a $\mathrm{TiO}_{2}$ concentration of $0.1 \mathrm{~g} / \mathrm{L}$. It was seen that the remaining phenol concentration after $60 \mathrm{~min}$ reaction time decreased from $32 \%$ of its initial value in the absence of US to $26.0 \%$ and $11.3 \%$ of the initial value at an US power of $50 \mathrm{~W}$ and $100 \mathrm{~W}$, respectively. As in Section 3.1, an evaluation of the reaction kinetics was carried out. Again, it was seen that the reactions all follow first order reaction kinetics. The values for the reaction rate constants $\mathrm{k}^{\prime}$ are reported in Table 1 . In analogy with the improvement of phenol degradation, the reaction rate constants increased with increasing US power.

Since the sole application of US did not result in a significant phenol degradation (see assays 24 and 25 in Table 2), it is clear that the observed improvements were due to an enhancement of the photocatalytic reaction. An influence of the US application on the direct photolysis is excluded as photolysis directly takes place by the interaction of UV photons with phenol molecules in the liquid phase, which is not governed by any mass transfer limitations. 


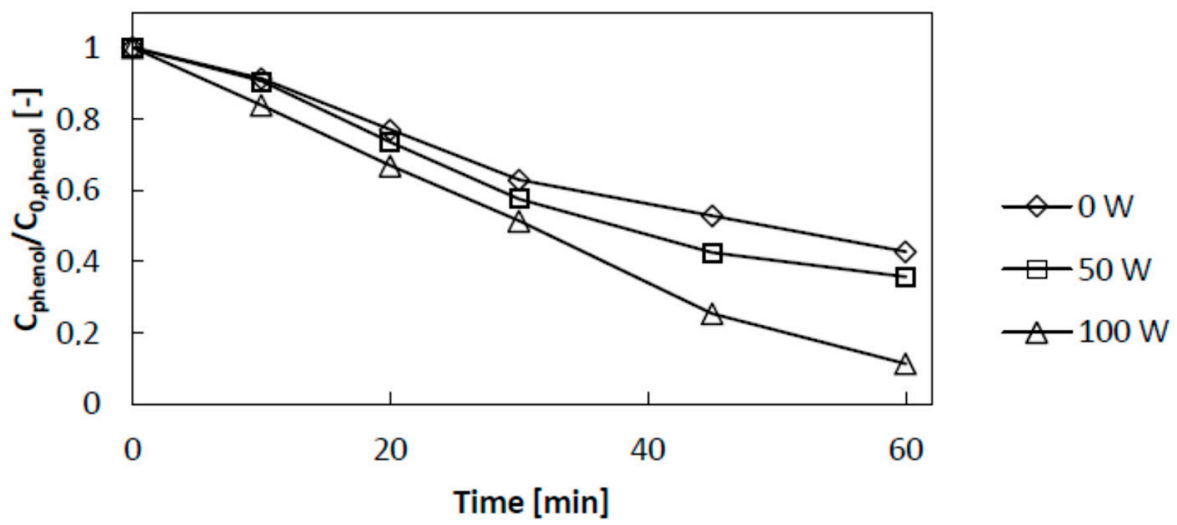

Figure 5. The degradation of phenol by $\mathrm{UV} / \mathrm{TiO}_{2} /$ ultrasound (US): comparison of different acoustic field powers $\left(0.1 \mathrm{~g} \mathrm{TiO}_{2} / \mathrm{L}\right)$.

To elucidate the mechanism underlying the observed improvement, the effects of US application on $\mathrm{TiO}_{2}$ deagglomeration were first studied by measuring the particle size distribution before and after the US treatment. The results are depicted in Figure 6. It was observed that the US treatment resulted in a significant decrease in the average particle size. Specifically, a large fraction of particles with a diameter between 0.1 and $0.8 \mu \mathrm{m}$ were generated. A bimodal distribution occurred. Also, reagglomeration of the particles did not occur within $1 \mathrm{~h}$ after the US treatment was stopped, since no significant change in the particle size distribution was found. This observation confirms the validity of the hypothesis that a deagglomeration of the photocatalyst takes place. Additionally, since no reagglomeration occurred after US treatment, this provides the opportunity to decouple deagglomeration and improve mass transfer as causes for the improvement in phenol degradation rate by US treatment.

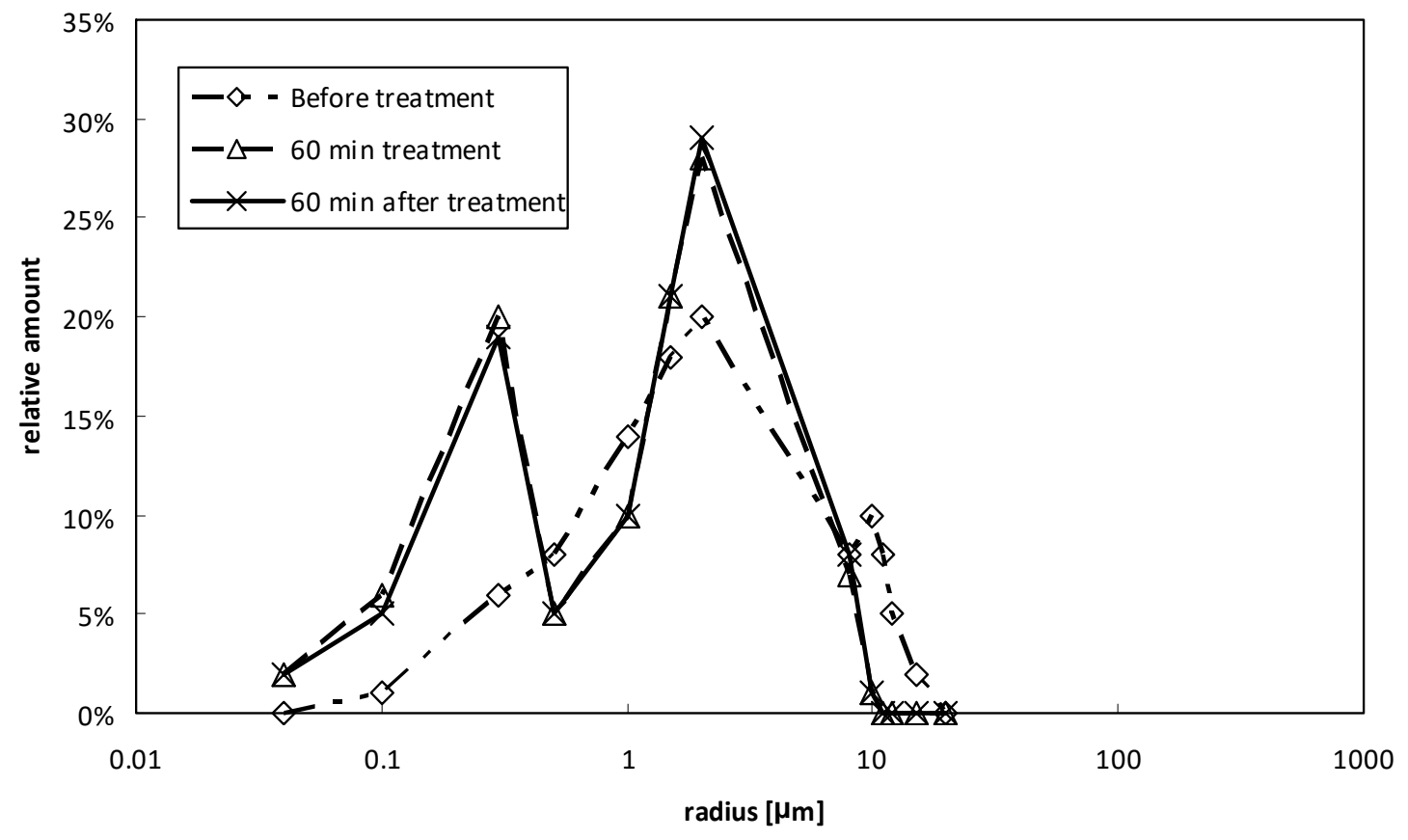

Figure 6. Particle size distribution before and after acoustic field treatment ( $30 \mathrm{~W}, 24 \mathrm{kHz})$.

To assess whether the observed improvement was mainly due to deagglomeration of the photocatalyst particles or due to an enhancement of the mass transfer, the following experimental plan consisting of three experimental runs was set up. In run 1, a typical photocatalytic degradation experiment was performed $(0.1 \mathrm{~g} / \mathrm{L} \mathrm{TiO} 2,11 \mathrm{~W} \mathrm{UV})$ without application of US. In run 2, the same conditions were kept, but a US power of $30 \mathrm{~W}$ was applied during the experiment. In run 3 , the $\mathrm{TiO}_{2}$ 
photocatalyst was first subjected to $30 \mathrm{~W}$ US power during $1 \mathrm{~h}$. Then the US was switched off and the UV lamp switched on to start the reactions with phenol. In run 2, the effect of the US treatment could be both due to deagglomeration and enhanced mass transfer, whereas in run 3, the US application could only have an effect due to deagglomeration of the $\mathrm{TiO}_{2}$.

The results of the three experimental runs are depicted in Figure 7. No significant differences were observed between the results of run 1 and run 3 . This means that the photocatalyst deagglomeration did not have a significant effect on the photocatalytic phenol degradation. Run 2 on the other hand showed a considerable increase in reaction rate. Since no differences in particle size distribution of the $\mathrm{TiO}_{2}$ were present between run 2 and run 3 , it should be concluded that this increase is due to an increase in the mass transfer rate.

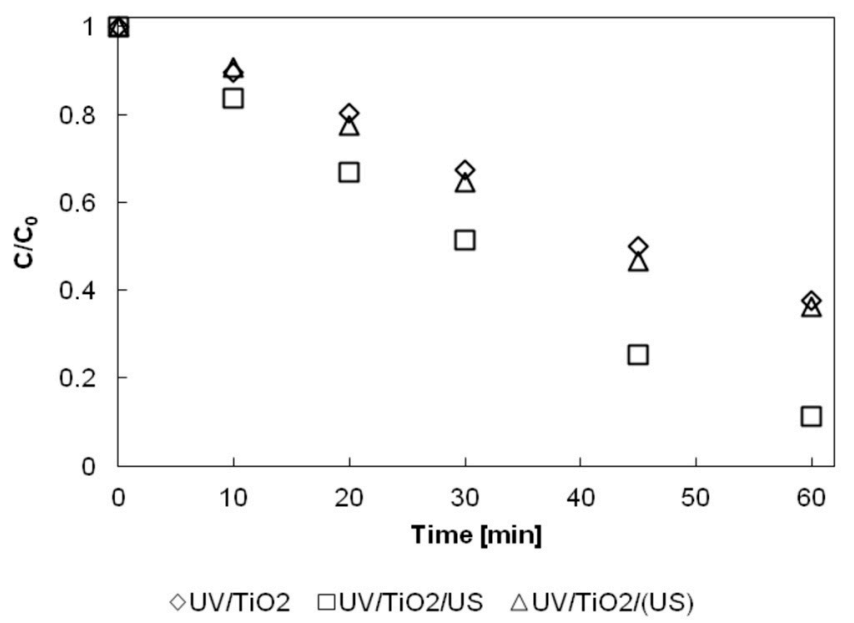

Figure 7. Comparison between photocatalysis $(\diamond)$, sono-photocatalysis $(\square)$, and photocatalysis $(\Delta)$ with sono-pretreated catalyst ( $30 \mathrm{~W}$ and $24 \mathrm{kHz}$ acoustic field, $0.1 \mathrm{~g} / \mathrm{L} \mathrm{TiO}_{2}, \mathrm{c}_{0}=5 \mathrm{ppm}$ phenol).

\subsection{Nature of the Photocatalytic Reaction}

The $\mathrm{TiO}_{2} / \mathrm{UV}$ photocatalytic degradation of phenol may be caused by two different reaction mechanisms: (i) a direct oxidation of phenol at the photocatalyst surface, or (ii) an indirect oxidation by $\mathrm{OH}^{*}$ radicals, which are generated at the photocatalyst surface. The reaction between $\mathrm{OH}^{*}$ and phenol can take place all over the reactor volume and not necessarily at the photocatalyst surface.

To investigate which mechanism is taking place, t-butanol was added to the solution before reaction (at a concentration of $1 \mathrm{~g} / \mathrm{L}$ ). This is a high concentration compared to the concentration of phenol. t-butanol is generally known to be a radical scavenger and will react much faster with the $\mathrm{OH}^{*}$ radicals than phenol, hence significantly reducing the apparent reaction rates of phenol with $\mathrm{OH}^{*}$. The results of phenol degradation tests by (a) direct photolysis, (b) photocatalytic degradation without US, and (c) photocatalytic degradation with US are depicted in Figure 8. All tests were carried out with and without the addition of t-butanol, and the phenol degradation between both was compared. The calculated first order reaction rate constants are presented in Table 3.

Table 3. Pseudo-first order rate constants with and without t-butanol.

\begin{tabular}{ccc}
\hline & $\mathbf{k}_{\text {with t-butanol }} \mathbf{( 1 / s )}$ & $\mathbf{k}_{\text {no t-butanol }} \mathbf{( 1 / s )}$ \\
\hline $\mathrm{UV}$ & 0.0123 & 0.01181 \\
$\mathrm{UV} / \mathrm{TiO}_{2}$ & 0.00443 & 0.01921 \\
$\mathrm{UV} / \mathrm{TiO}_{2} / \mathrm{US}$ & 0.00473 & 0.02235 \\
\hline
\end{tabular}



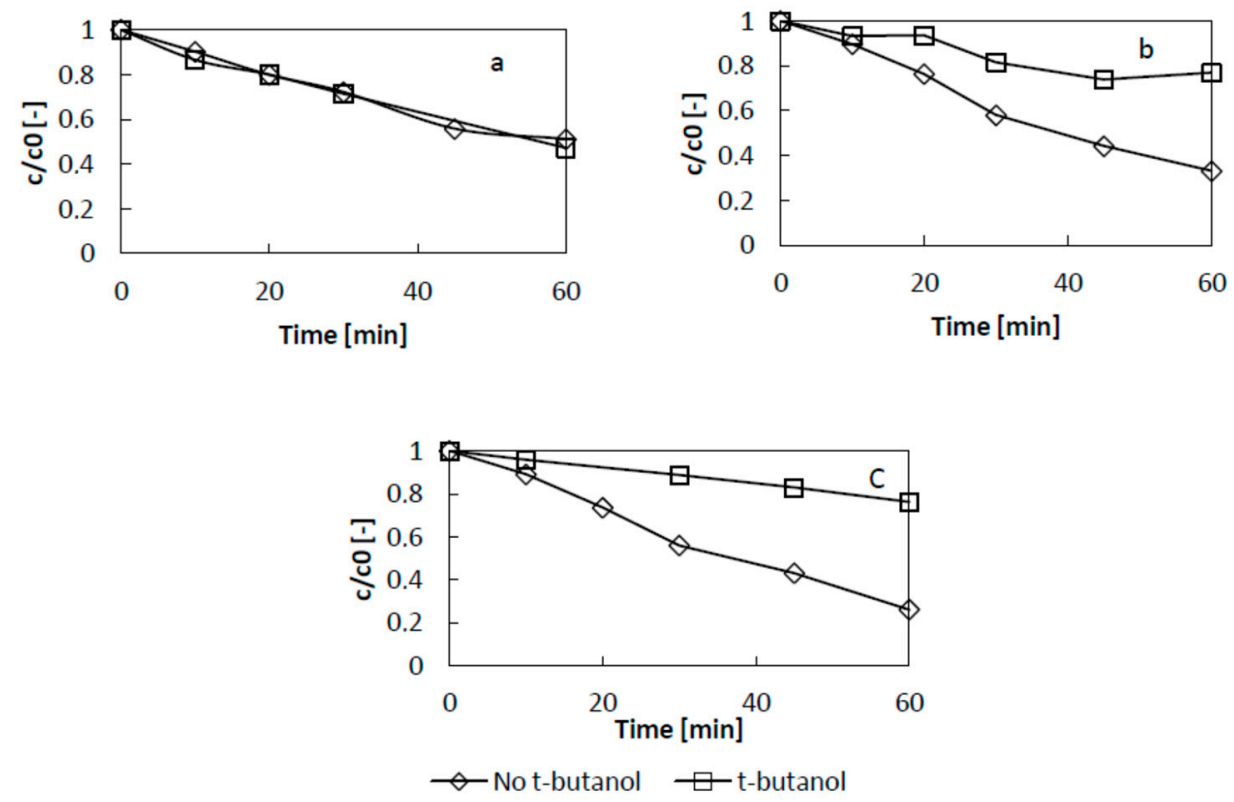

Figure 8. Phenol degradation in the presence of $1 \mathrm{~g} / \mathrm{L} \mathrm{t}$-butanol with different operating conditions: (a) UV alone, (b) $\mathrm{UV} / \mathrm{TiO}_{2}(0.1 \mathrm{~g} / \mathrm{L})$, and (c) $\mathrm{UV} / \mathrm{TiO}_{2} / \mathrm{US}(0.1 \mathrm{~g} / \mathrm{L}$ and $50 \mathrm{~W})$.

The presence of t-butanol did not affect the phenol degradation rate for direct photolysis, i.e., in absence of photocatalyst. The degradation curves in Figure 8a did not differ significantly and the reaction rate constants were very similar. This is, however, no longer the case for both photocatalytic systems, with and without US application. Here, a significant decrease in the apparent reaction rate was observed in the presence of t-butanol (Figure $8 b, c)$. The first order reaction rate constant $k^{\prime}$ decreased from $0.019 \mathrm{~s}^{-1}$ to $0.0044 \mathrm{~s}^{-1}$ for the $\mathrm{UV} / \mathrm{TiO}_{2}$ system and from $0.022 \mathrm{~s}^{-1}$ to $0.0047 \mathrm{~s}^{-1}$ for the $\mathrm{UV} / \mathrm{TiO}_{2} / \mathrm{US}$ system. This observation leads to the conclusion that the photocatalytic degradation of phenol mainly takes place by means of $\mathrm{OH}^{*}$ radicals. Since the reaction rates were still higher than for UV application solely (direct photolysis), some direct photocatalytic degradation is taking place at the catalyst surface. The exact location of the reaction (directly at the photocatalyst surface or in the bulk of the liquid) cannot be determined based on these kinetic experiments, as was already pointed out by Malato et al. [11]. Basically, this is due to the fact that the Langmuir-Hinshelwood equation resembles too much to the (pseudo) first order equation for radical oxidation in the bulk solution.

\subsection{Multivariate Statistical Analysis}

The obtained experimental results are further used to identify the most important parameters and to develop a surface response model to predict the decrease in phenol concentration as a function of time. The calculations are based on the experimental data reported in Table 2. In Figure 9, the main effect plots (data means) are depicted, representing the influence of each variable on the phenol degradation. This mathematical assessment confirms the observations and conclusions previously presented in this manuscript. The relative importance of the studied parameters was assessed in a Pareto chart, depicted in Figure 10. Next to the individual parameters, interaction parameters were included in the analysis. It is observed that the US most significantly influenced the phenol degradation, followed by the reaction time. A 95\% significance level was chosen for the analysis. The analysis leads to the model expressed in Equation (4).

$$
\frac{c}{c_{0, \text { cal }}}=1.00-0.000898 \times C-0.00838 \times A-0.000554 \times C D+0.0099 \times B D-0.0071 \times D
$$



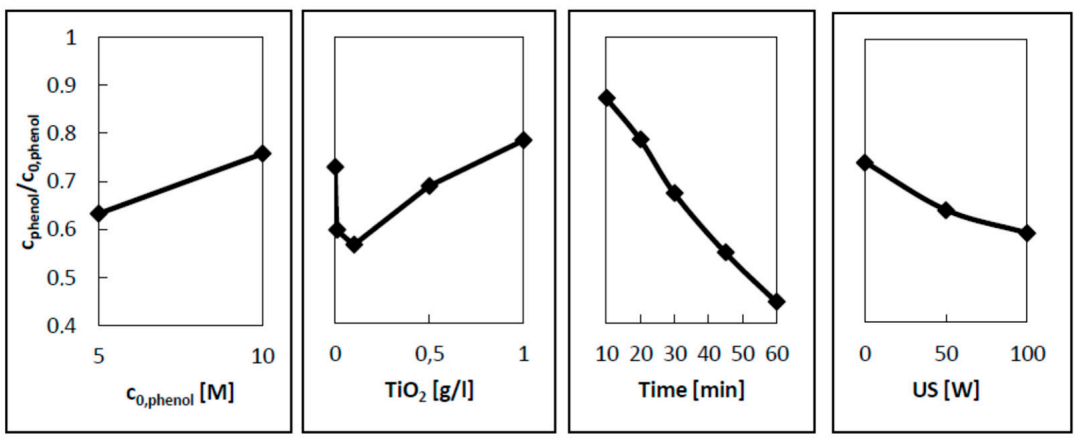

Figure 9. Main effects plot.

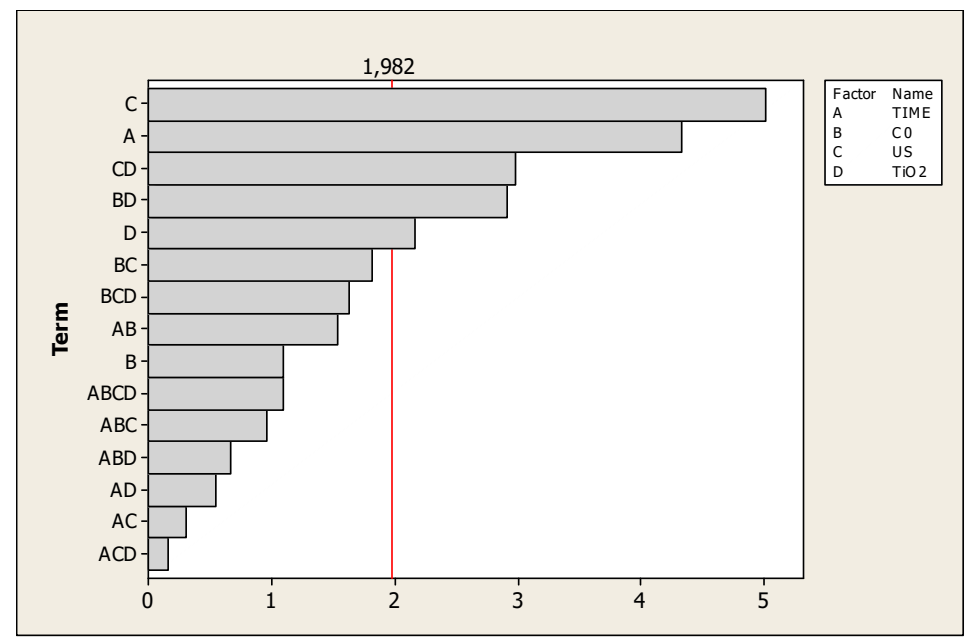

Figure 10. Pareto chart for the experiments.

In this equation, $A, B, C$, and $D$ stand for time, initial phenol concentration, ultrasound effects, and $\mathrm{TiO}_{2}$ dosage, respectively. The effectiveness of the model is shown in Figure 11. As indicated in this figure, the model provided the best results at low phenol conversion $\left(C / C_{0}\right.$ large), whereas it tended to overestimate the degradation at high phenol conversion $\left(C / C_{\mathrm{o}}\right.$ small).

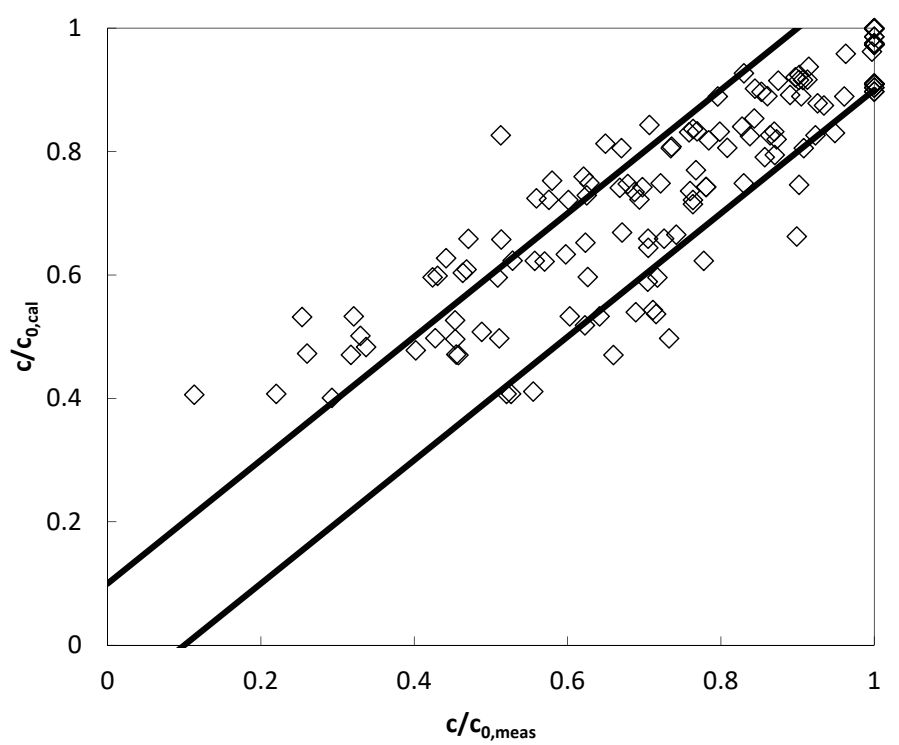

Figure 11. Correlation between $C / C_{0, \text { cal }}$ and $C / C_{0, \text { meas }}$. 


\section{Conclusions}

In this work, the photocatalytic degradation of phenol by $\mathrm{TiO}_{2}$ photocatalysis was assessed, and the influence of US treatment evaluated. An optimal concentration of photocatalyst dosage was shown. The degradation rate when $0.1 \mathrm{~g} / \mathrm{L}$ was applied, was twice as high compared to when $1 \mathrm{~g} / \mathrm{L}$ was applied. The reason for this higher reaction rate, is the influence of the mass that receives sufficient UV light. If the concentration of catalyst is too high, the light intensity decreases very fast, compared to when less catalyst is used.

When a low frequency acoustic field was applied, the degradation rate increased with increasing power. This faster degradation was only visible when the acoustic field was applied at the same time as when the UV light was used. When the catalyst was pre-treated with US, and then used for photo-catalysis, the degradation rate was the same compared to when no US was applied to pre-treat the photocatalyst. US treatment was able to effectively increase the phenol degradation rate, due to an improvement of mass transfer while particle deagglomeration did not play a significant role. The photocatalytic degradation mainly occurred through indirect phenol oxidation by $\mathrm{OH}^{*}$ radicals, which were formed in situ at the surface of the photocatalyst. The experiments involving the application of $\mathrm{t}$-butanol, as a hydroxyl radical scavenger, confirmed that a combination of three different mechanisms, i.e., adsorption, chemical oxidation by the generated radicals, and direct photolysis, are responsible for the phenol removal.

In the final part of the research, a mathematical model of phenol degradation was developed. The model was based on the partial least squares (PLS) methodology. The model provides the best results at low phenol conversion $\left(C / C_{o}\right.$ large), whereas it tends to overestimate the degradation at high phenol conversion $\left(\mathrm{C} / \mathrm{C}_{\mathrm{o}}\right.$ small).

Author Contributions: Conceptualization, W.V.d.M., J.D., J.L. and R.D.; methodology, W.V.d.M., J.D. and J.L.; sample analyses, L.B. and K.S.; experimental investigation, W.V.d.M.; writing-original draft preparation, W.V.d.M. and R.D.; writing-review and editing, M.K., J.D., J.L., K.S., L.B. and R.D.; supervision, J.D., J.L. and R.D. All authors have read and agreed to the published version of the manuscript.

Funding: This research was funded by the Agency for Innovation by Science and Technology Flanders, grant number IWT/093025 and by the Industrial Research Fund of KU Leuven, grant number KP/10/006.

Conflicts of Interest: The authors declare no conflict of interest. The funders had no role in the design of the study; in the collection, analyses, or interpretation of data; in the writing of the manuscript, or in the decision to publish the results.

\section{References}

1. Scott, T.; Zhao, H.; Deng, W.; Feng, X.; Li, Y. Photocatalytic degradation of phenol in water under simulated sunlight by an ultrathin $\mathrm{MgO}$ coated $\mathrm{Ag} / \mathrm{TiO} 2$ nanocomposite. Chemosphere 2019, 216, 1-8. [CrossRef]

2. Busca, G.; Berardinelli, S.; Resini, C.; Arrighi, L. Technologies for the removal of phenol from fluid streams: A short review of recent developments. J. Hazard. Mater. 2008, 160, 265-288. [CrossRef] [PubMed]

3. Mohammed, N.A.S.; Abu-Zurayk, R.A.; Hamadneh, I.; Al-Dujaili, A.H. Phenol adsorption on biochar prepared from the pine fruit shells: Equilibrium, kinetic and thermodynamics studies. J. Environ. Manag. 2018, 226, 377-385. [CrossRef] [PubMed]

4. Praveen, P.; Loh, K.C. Solid/liquid extraction equilibria of phenolic compounds with trioctylphosphine oxide impregnated in polymeric membranes. Chemosphere 2016, 153, 405-413. [CrossRef] [PubMed]

5. Chen, C.; Yao, X.; Li, Q.X.; Wang, Q.; Liang, J.; Zhang, S.; Ming, J.; Liu, Z.; Deng, J.; Yoza, B.A. Turf soil enhances treatment efficiency and performance of phenolic wastewater in an up-flow anaerobic sludge blanket reactor. Chemosphere 2018, 204, 227-234. [CrossRef] [PubMed]

6. Ersöz, G.; Atalay, S. Treatment of aniline by catalytic wet air oxidation: Comparative study over $\mathrm{CuO} / \mathrm{CeO} 2$ and $\mathrm{NiO} / \mathrm{Al}_{2} \mathrm{O}_{3}$. J. Environ. Manag. 2012, 113, 244-250. [CrossRef] [PubMed]

7. Chicinas, R.P.; Gál, E.; Bedelean, H.; Darabantu, M.; Măicăneanu, A. Novel metal modified diatomite, zeolite and carbon xerogel catalysts for mild conditions wet air oxidation of phenol: Characterization, efficiency and reaction pathway. Sep. Purif. Technol. 2018, 197, 36-46. [CrossRef] 
8. Bai, C.P.; Xion, X.F.; Gong, W.Q.; Feng, D.X.; Xian, M.; Ge, Z.X.; Xu, N.A. Removal of rhodamine B by ozone-based advanced oxidation processes. Desalination 2011, 278, 84-90.

9. Dewil, R.; Mantzavinos, D.; Poulios, I.; Rodrigo, M. New perspectives for Advanced Oxidation Processes. J. Environ. Manag. 2017, 195, 93-99. [CrossRef]

10. Chou, M.Y.; Chang, C.Y. Photocatalytic degradation of 2-chloro and nitrophenol by titanium dioxide suspensions in aqueous solution. Appl. Catal. B Environ. 1999, 21, 1-8.

11. Malato, S.; Fernández-Ilbanez, P.; Maldonado, M.I.; Blanco, J.; Gernjack, W. Decontamination and disinfection of water by solar photocatalysis: Recent overview and trends. Catal. Today 2009, 147, 1-59. [CrossRef]

12. Chun, H.; Yizhong, W.; Hongxiao, T. Destruction of phenol aqueous solution by photocatalysis of direct photolysis. Chemosphere 2000, 41, 1205-1209. [CrossRef]

13. Ayyildiz, O.; Sanik, S.; Ileri, B. Effect of Ultrasonic pretreatment on chlorine dioxide disinfection efficiency. Ultrason. Sonochemistry 2011, 18, 693-698. [CrossRef] [PubMed]

14. Vassilakis, C.; Pantidou, A.; Psillakis, E.; Kalogerakis, N.; Mantzavinos, D. Sonolysis of natural phenolic compounds in aqueous solutions: Degradation pathways and biodegradability. Water Res. 2004, 38, 3110-3118. [CrossRef]

15. Rasheed, Q.J.; Pandian, K.; Murhukumar, K. Treatment of petroleum refinery wastewater by ultrasound-dispersed nanoscale zero-valent iron particles. Ultrason. Sonochemistry 2011, 18, 1138-1142. [CrossRef]

16. Matouq, M.; Al-Ayed, O.; Al-Anber, Z.; Al-Shannag, M.; Kloub, N.; Tagawa, T.; Aljbour, S. Wastewater treatment resulting from an oil shale restoring at high frequency ultrasound waves with a chemical elemental analysis. Energy Sources Part A: Recovery Util. Environ. Eff. 2010, 32, 1878-1884. [CrossRef]

17. Guo, H.G.; Gao, N.Y.; Li, L.; Jin, X.; Chen, Z. Degradation of chlorothalonil by ultrasonic irradiation: Kinetics and impact factors. J. Cent. South Univ. Technol. 2011, 18, 1068-1073. [CrossRef]

18. Suslick, K.S. The chemical effects of ultrasound. Sci. Am. 1989, 260, 80-86. [CrossRef]

19. Appels, L.; Houtmeyers, S.; Van Mechelen, F.; Degrève, J.; Dewil, R. Effects of Ultrasonic pre-treatment on the sludge characteristics and anaerobic digestion. Water Sci. Technol. 2012, 66, 2284-2290. [CrossRef]

20. Sauter, C.; Emin, M.A.; Schuchmann, H.P.; Tavman, S. Influence of hydrostatic pressure and sound amplitude on the ultrasound induced dispersion and de-agglomeration of nanoparticles. Ultrason. Sonochemistry 2008, 15, 517-523. [CrossRef]

21. Madhavan, I.; Theerthagiri, J.; Balaji, D.; Sunitha, S.; Choi, M.Y.; Ashokkumar, M. Hybrid advanced oxidation processes involving ultrasound: An overview. Molecules 2019, 24, 3341.

22. Kidak, R.; Ince, N.H. Effects of operating parameters on sonochemical decomposition of phenol. J. Hazard. Mater. 2006, 137, 1453-1457. [CrossRef] [PubMed]

23. Harada, H.; Tanaka, H. Sonophotocatalysis of oxalic acid solution. Ultrasonics 2006, 44, 385-388. [CrossRef] [PubMed]

24. Mrowetz, M.; Pirola, C.; Selli, E. Degradation of organic water pollutants through sonophotocatalysis in the presence of $\mathrm{TiO}_{2}$. Ultrason. Sonochemistry 2003, 10, 247-254. [CrossRef]

25. Na, S.; Ahn, Y.G.; Cui, M.; Khim, J. Significant Diethyl Phthalate (DEP) degradation by combined advanced oxidation processes in aqueous solution. J. Environ. Manag. 2012, 101, 104-110. [CrossRef]

26. Taghizadeh, M.T.; Abdollahi, R. Sonolytic, Sonocatalytic and sonophotocatalytic degradation of chitosan in the presence of TiO2 nanoparticles. Ultrason. Sonochemistry 2011, 18, 149-157. [CrossRef]

(C) 2020 by the authors. Licensee MDPI, Basel, Switzerland. This article is an open access article distributed under the terms and conditions of the Creative Commons Attribution (CC BY) license (http://creativecommons.org/licenses/by/4.0/). 